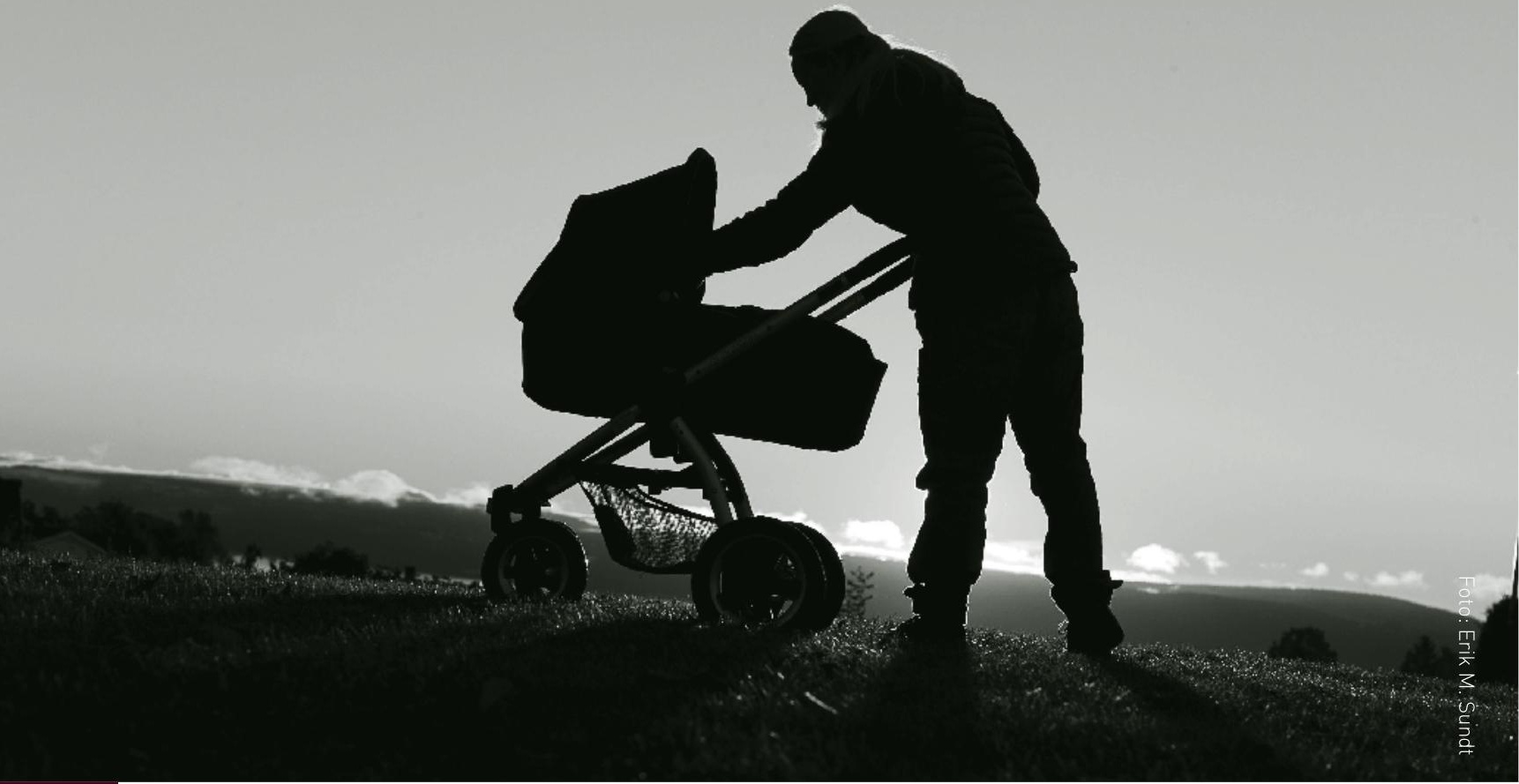

Bakgrunn: Overgang fra føde/ barselavdeling til helsestasjonen i kommunehelsetjenesten overtar oppfølging av barnet og familien, viser store gap og synes tilfeldig innhold og kvalitet.

Hensikt: $\AA$ utforske mødres erfaringer den første tiden hjemme med en nyfødt.

Metode: Klassisk Grounded theory ble brukt ved innsamling og bearbeiding av data fra sju fokusgrup- peintervju med 26 mødre med barn i alderen seks uker til tre måneder.

Resultat: Mødrene var sterkt opptatt av å bevare kontroll og integritet i sin nye situasjon. Dette hovedproblemet ble håndtert med strategien «Prioritering av nyfødtomsorg». Strategien omfatter prosessene: utvikler kompetanse, endrer fokus i parforholdet, tøyer tålegrenser og søker anerkjennelse. Disse parallelle prosessene hadde innbyrdes sammenheng, noen ganger til gjensidig støtte og andre ganger i konflikt.

Konklusjon: For å lykkes med amming og gi omsorg til barnet, kan mødre ignorere grunnleggende behov som å spise og sove og utholde smerter. Forestillingen om at å føde barn er en normal situasjon kan ha ført til usynliggjøring av barselkvinnen og undervurdering av foreldres behov den første sårbare tiden og dermed forhindre å gi et helhetlig tilbud med profesjonell omsorg og informasjon.
The importance of post-natal women the first period at home with a newborn

Background: There is a significant gap in the continuance of patient care from discharge from the maternity unit until the health centre provides follow-up for the family and the baby.

Objective: The article aims to explore how mothers experience the first period at home with their newborn.

Method: The classical grounded theory method was used to gather and analyse data. Seven focus group discussions were conducted with 26 mothers who had babies 1.5-3 months old.

Results: The mothers were strongly concerned about preserving their control and integrity in the new situation. This main concern was resolved by the strategy of prioritizing newborn care. The strategy encompassed a process of developing competence in motherhood, changing focus in relationships, stretching to the critical level and seeking recognition. These parallel processes were interrelated, sometimes mutually supportive and sometimes conflicting.
Conclusion: While succeeding in breastfeeding and taking care of the baby, mothers will ignore basic needs to eat and sleep, and suppress pains. The idea that giving birth is a simple and normal situation may obscure the postnatal woman, underestimate the importance of parents' need in a vulnerable period and thereby hinder seamless health care and the professional support and information.

Keywords: Post-natal woman, newborn, health services, breastfeeding, grounded theory 


\section{Hva barselkvinner er opptatt av den forste tiden hjemme med en nyfodt}

Forfattere: Esther Hjälmhult og Toril Økland

\section{NøKKELORD}

- Nyfødt

- Helsetjeneste

- Amming

- Fokusgrupper

- Grounded theory

\section{BAKGRUNN}

I de siste åtte-ti årene har barselomsorgen gradvis blitt redusert ved norske sykehus. I dag er barseloppholdet på to-tre dager, med en variasjon på null-sju dager. En tilsynsrapport fra Statens helsetilsyn beskriver at overgang fra føde/barselavdeling til helsestasjon i kommunehelsetjenesten viser store gap og synes tilfeldig $\mathrm{i}$ innhold og kvalitet (1).

Forskning viser at mange mødre har økt sårbarhet etter en fødsel, der særlig det første barnet medfører store omstillinger i familiens liv. Ro og omsorg i barseltiden synes å beskytte mot depressive plager etter fødselen, og sosial støtte og tro på seg selv demper stress og engstelse (2-6). Mangel på grunnleggende omsorg på sykehuset har vist en negativ effekt på mors selvfølelse og hennes tro på seg selv som mor (7-8). I slike tilfeller ble det sosiale nettverket deres lite brukt, og mødrene prioriterte ikke hvile og ro til å amme i barseltiden (7).

I barseltiden rapporterer mødre at det er vesentlig å kjenne trygghet, og at ulike og motstridende råd, særlig om amming, gir usikkerhet (9-10). Ammeproblemer i starten, med smerter og sårhet, uro for tilstrekkelig melkemengde og brystbetennelse, skal kunne pareres med andre fysiske endringer og plager (1112). Studier viser også at mødre er lite forberedt på hva som ventet dem etter hjemkomst, og hvordan de skal håndtere vanlige problemer både i forhold til seg selv og til barnet (13-16).

Vi mangler kunnskapsbaserte retningslinjer for den endrete barselomsorgen. Noen studier rapporterer at tidlig tilrettelagt hjemreise etter en fødsel ikke har negative konsekvenser for mor og barn (17-20), mens andre studier viser manglende evidens, og at mødres helse neglisjeres og legekontakter eller sykehusinnleggelse av mor og den nyfødte øker (21-23). For å møte nybakte familiers behov er det en lovbestemt oppgave i Norge å tilby hjemmebesøk til alle familier helst innen to uker etter fødsel (24). I noen kommuner er likevel hjemmebesøk redusert (25). Når både spesialisthelsetjenesten og kommunehelsetjenesten reduserer ytelsene til nye familier, er det viktig å få kunnskap om hvordan aktuell praksis møter foreldres behov. På den måten kan man støtte brukerne og tilpasse helsetjenesten. Hensikten med studien var derfor å undersøke hvordan mødre erfarer den første tiden hjemme etter en fødsel og hvordan de håndterer sin nye situasjon. En mer detaljert beskrivelse er publisert tidligere (26).

\section{METODE}

$\mathrm{Vi}$ valgte klassisk grounded theory for å utforske latente sosiale prosesser. Målet er ikke bare å beskrive, men også å generere teori som forklarer atferdsmønsteret til de studerte. Datainnsamling og analyse skjer samtidig ved at vi konstant sammenlikner likheter, forskjeller og grader av konsistens mellom indikatorer. Teorien genereres induktiv på bakgrunn av relasjoner som er

\section{Hva tilfører artikkelen?}

Artikkelen viser blant annet at det å lykkes med amming synes å være en særlig følsom og viktig del av morsrollen, og for å lykkes med amming og gi omsorg til barnet, kan mødre ignorere grunnleggende behov hos seg selv som å spise og sove og utholde smerter.

\section{Mer om forfatter:}

Esther Hjälmhult er dr. polit, helsesøster og førsteamanuensis ved Avdeling for helse- og sosialfag, institutt for sykepleiefag og ved Senter for kunnskapsbasert praksis, Høgskolen i Bergen. Toril $\emptyset k$ land er helsesøster med master i helsefremmende arbeid. Hun er enhetsleder helsestasjons-og skolehelsetjenesten i Bergen kommune. Kontakt: ehjahib.no. 
empirisk forankret $(27,28)$. Vi vurderte fokusgrupper som hensiktsmessig for datainnsamlingen, der interaksjonen mellom deltakerne var sentralt for å åpne opp for ny innsikt. Fokusgruppeintervjuer og analyser var rettet mot å forstå deltakernes perspektiv uten et gitt teoretisk perspektiv (29).

\section{DELTAKERE}

Deltakerne ble rekruttert på helsestasjoner i ulike bydeler der mødre fikk skriftlig informasjon tre-seks uker etter fødselen. Tjueseks mødre med spedbarn deltok i sju fokusgrupper. Kriterier var norsktalende mødre over 18 år med barn fra seks uker til tre måneder. $\mathrm{Ti}$ av deltakerne var førstegangsmødre, 16 hadde to til fire barn. Mødrene var 20-40 år, hadde variert demografisk bakgrunn, men ingen var alenemødre. Variasjonen var ellers rik med ulike erfaringer fra normale fødsler, keisersnitt, tvillinger og lett premature. Mødrene hadde født på en stor institusjon med utreise innen 48 timer, unntatt enkelte som ble lengre på grunn av komplikasjoner.

\section{DATASAMLING OG ANALYSE}

Vi vektla et avslappende miljø og aktiv lytting for å tilrettelegge for interaksjonen i gruppen (29, 30). Inngangsspørsmålet i gruppene var: «Hvordan har det vært å komme hjem med en nyfødt?» Diskusjonene gikk livlig. Fokusgruppeintervjuene varte halvannen time, ble tatt opp på bånd og transkribert, og de fem første gruppene dannet et grunnlag for å utvikle hypoteser om hva som skjer i det studerte feltet.

Analysen består av åpen, selektiv og teoretisk koding (tabell 1). Vi startet med en åpen kodingsprosess hvor hvert intervju ble analysert og sammenliknet med de tidligere, kombinert med skrevne memo, alt i en kontinuerlig prosess. Vi identifiserte deltakernes hovedproblem den første tiden hjemme med en nyfødt, for deretter å identifisere den såkalte kjernekategorien som kunne fange det handlingsmønster som mødrene anvendte for å håndtere problemet (27). I analyseprosessen ble kodene gruppert i større kategorier, der beskrivende koder som «ber om hjelp ved amming», «lærer å håndpumpe» ble utviklet til mer teoretiske begreper som «utvikler ferdigheter» eller «utvikler kompetanse». Ved selektiv koding konsentrerte vi analysene omkring relasjoner til kjernekategorien, og til slutt kodet vi teoretisk om relasjoner mellom kategoriene. De to siste fokusgruppene anvendte vi til å sikre variasjon i demografiske data og berike de framkomne koder og hypoteser mot teoretisk metning, det vil si at det ikke kom fram nye kategorier fra intervjuene. Hensikten med teoretisk koding er å relatere kodene til hverandre på en slik måte at teorien stemmer med data og er relevant, ved å la mønstre eller prosesser framstå og fungere slik at de forklarer hva som pågår i det studerte feltet (28).

Andre medforfatter var comoderatorer i gruppene, assisterte ved enkel servering og noterte stikkord og eventuelle spørsmål vi diskuterte i etterkant. Studien er meldt til Norsk samfunnsvitenskapelig datatjeneste, men vurdert utenfor mandatet til Regional Etisk Komité. (Se tabell 1.)

\section{FUNN}

Hovedproblem for mødrene ble identifisert til «hvordan kan de bevare kontroll og integritet i sin nye livssituasjon?». De prøvde å håndtere dette hovedproblemet med «Prioritering av nyfødtomsorg», en prosess som omfatter fire atferdsmønstre: «utvikler kompetanse", "endrer fokus i parforhold», «tøyer tålegrenser» og «søker anerkjennelse».

\section{Forhold som påvirker}

Karakteristiske forhold som påvirket prioritering av nyfødtomsorg var mødrenes opplevelse av å være sårbare og slitne den første tiden. De ble også lett stresset. Mange uttalte at de ville reise tidlig hjem etter fødselen, men særlig førstegangsmødre var likevel lite forberedt på opplevelsen av stress og utrygghet. Mange av dem visste lite og var usikre og engstelige for ikke å mestre omsorg og stell av barnet.

Førstegangsmødre opplevde intense dager, og flergangsmødre
TABELL 1: Faser i analysen ved grounded theory.

\begin{tabular}{|c|c|c|}
\hline Faser & Hensikt & Resultat \\
\hline \multicolumn{3}{|l|}{ 1. Substantiv koding } \\
\hline - Åpen koding & $\begin{array}{l}\text { Utvikle substantive koder } \\
\text { og kategorier og deres } \\
\text { egenskaper }\end{array}$ & $\begin{array}{l}\text { Opplever sårbarhet, tøyer } \\
\text { tålegrenser og sammen- } \\
\text { ligner babyer }\end{array}$ \\
\hline - Selektiv koding & $\begin{array}{l}\text { Utvelge koder relatert til } \\
\text { kjernekategorien }\end{array}$ & $\begin{array}{l}\text { Bare relevante koder: } \\
\text { Opplever sårbarhet, tøyer } \\
\text { tålegrenser }\end{array}$ \\
\hline 2. Teoretisk koding & $\begin{array}{l}\text { Formulere hypoteser som } \\
\text { beskriver relasjoner mellom } \\
\text { substantive kategorier }\end{array}$ & $\begin{array}{l}\text { Jo mer tøyde tålegrenser, } \\
\text { jo mer opplevd sårbarhet }\end{array}$ \\
\hline
\end{tabular}


en mer maset hverdag. For mange var det en belastning å ta seg tilbake til sykehuset fire-fem dager etter fødselen for blodprøvescreening av barnet, og ved hyperbilerubin var det daglige reiser. Andre forhold som spilte inn var relatert til barnets og mors velvære, hvordan amming fungerte og mors muligheter for søvn og avlastning.

\section{Utvikler kompetanse}

Kompetanseutvikling i morsrollen var særlig preget av a) å søke informasjon og servicetilbud, b) å utvikle ferdigheter. Mødrene søkte aktivt informasjon om ulike forhold etter en fødsel som angikk dem selv og barnet. De orienterte seg om servicetilbud og kontakter ved eventuelle akutte situasjoner. Flere hadde søkt legevakt, barneklinikk, homøopat eller lege utover henvendelser til helsestasjonen. Andre kontaktet apotek ved bekymringer. Mors fastlege ble med få unntak ikke kontaktet i forhold til babyen. Helsestasjonstilbudene var uklare for noen, og mødrene anbefalte at helsestasjonen ble tydeligere ved hjelp av bedre PR. Flergangsmødre hadde gjerne større fleksibilitet enn de først hadde forventet.

Kommunehelsetjenestens servicetilbud om hjemmebesøk av helsesøster ble oftest positivt omtalt. Det var informativt og trivelig, og det var godt å få service «på døren». Enkelte uttrykte imidlertid ambivalens $\mathrm{i}$ forhold til å ha en offentlig person i sitt hjem. Noen som ikke hadde fått tilbudet til første barn, undret over hvorfor de fikk hjembesøk til det neste. Andre undret seg over hvorfor en ny helsesøster avtalte hjemmebesøk når deres "gamle» helsesøster var på kontoret ved siden av. De ville velge selv, men sa det neppe direkte. Der kontakten allerede var opparbeidet, ville de møte samme helsesøster.

Førstegangsmødre var opptatt av å lære praktiske ferdigheter i omsorgen for barnet. For øvrig var amming det største diskusjonstemaet for mødrene, uavhengig av antall barnefødsler. Noen hadde gode erfaringer, mens andre beskrev en hard læreperiode med såre og ømme bryst, engstelse for å mislykkes, og for om barnet «fikk nok». Kumelkallergi hos søsken kunne være ekstra motivasjon for å holde ut, selv om bare tanken på amming stresset dem.

\section{Parforholdet}

Parforholdet ble forandret, særlig etter det første barnet. De karakteristiske mønstre var a) endrer fokus i samlivet, b) overlater ansvar og c) verdsetter nytt fellesskap. Et typisk utsagn var:

«Det er en annen hverdag med barn, et helt annet fokus og stor forskjell fra å være kjærester til å bli foreldre. Det er ikke negativt, bare to forskjellige verdener.»

Mange framholdt hvordan far viste omsorg og gledet seg over pappapermisjonen. Når de ble

\section{I de siste åtte-ti årene har barselomsorgen gradvis blitt redusert ved norske sykehus.}

Helsesøster hadde teoretiske råd, men kanskje mindre praktiske ferdigheter. Å lykkes med amming syntes å ha nær sammenheng med å føle seg vellykket som mor. Mødrene diskuterte holdninger til amming og morsmelktillegg, utholdenhet, tvil og skuffelse over egen melkeproduksjon og glede når de lyktes. De verdsatte at helsestasjonene hadde en pragmatisk holdning til bruk av hjelpemidler, og henviste til at man på sykehuset hadde en tendens til å se ned på det «unaturlige».

Mødrene diskuterte morsfølelse som forklaring på at de var så på pletten i forhold til babyen. Noen ble overrasket over sterke følelser. En kunne godt huske fra tidligere at morsfølelsen uteble, med mye gråt og lite glede over barnet, men kunne ikke si det til noen. Redselen for å være unormal var stor. De snakket også om eksistensielle spørsmål. Hvordan skulle de klare ansvar og forventninger? Søken etter informasjon og servicetilbud bidro således til at mange etter hvert hadde funnet en viss ro og kontroll over situasjonen og utviklet kompetanse i morsrollen. alene igjen i hverdagen hadde mødrene forventninger om ulike aktiviteter. Men de kunne overrumplet registrere at når mannen kom hjem fra jobb, hadde de selv seg «skikkelig».

Kjærligheten ble det lite tid til, de glemte nesten at de var to. Først om kvelden kom de på at de ikke hadde gitt hverandre en klem engang, og de spiste på skift. Soving på skift var også vanlig, eller at de sov hver for seg fordi far skulle på jobb og «måtte sove», eller han snorket og forstyrret. Mor beskrev ofte at hun hadde døgnvakt. Andre diskuterte hvordan de delte på «byssing» og stell av barnet. På tross av lite tid og overskudd til kjærlighetsliv, var det likevel mødre som hadde begynt med prevensjon.

Tilpasninger i parforholdet angikk fars engasjement $i$ barnet og mors opplevelse av ansvar. Det var mange kommentarer om at mor overvåket når far stelte barnet, hun pirket lett og ga råd om hvordan det skulle gjøres. Flerbarnsmødre stolte mer på far, men han måtte vise seg verdig verken laget middag eller kledd 
ansvaret. Særlig førstegangsforeldre opplevde en ny dimensjon i samlivet. Forholdet ble styrket, de hadde fått noe nytt og felles å være glad i. Selv om mor var hovedpersonen, fant mange løsninger i fellesskap, når mor bare slapp far til.

\section{Tøyer tålegrenser}

Dette atferdsmønsteret var særlig preget av a) nedprioritering av behov, b) utholde smerter, usikkerhet og bekymringer. Mødre syntes å nedprioritere egne behov for mat og søvn og holde ut smerter og ubehag. De første to-tre månedene var intense. Særlig smertefullt det var å sitte på grunn av sting, og at de hadde hatt store vansker med toalettbesøk: «Er det normalt? Jeg begynte å bli engstelig, begynte å grine. Det var forferdelig. Jeg visste ikke at det var slik for noen - jeg hadde det ikke slik sist».

Når barnet ikke orket å suge, skulle det mye til før mor ga seg. Hun pumpet ut melk og ga barnet. Det føltes som nederlag å ikke gi morsmelk, og mor var derfor utholdende: «Jeg var mer utålmodig før. Det du må, det må du.»

$\AA$ tøye grensene sine hadde en pris, og noen tøyde strikken langt. På tross av dette var ikke

\section{Mange foreldre erfarte at de var lite forberedt på den forste tiden hjemme.}

førstegangsmødre kunne overse spising og glemme å ta vare på seg selv: "Jeg hadde ikke sjanse til å få i meg mat, eller ... jeg klarte ikke å sørge for det, hver gang jeg satte meg til å spise, så skjedde det noe, det gikk veldig i ett».

Det kunne forklare hvorfor mødrene kunne kjenne seg svimle. De prioriterte barnets behov framfor sine egne. De erfarne mødrene fikk lettere i seg mat. Et annet tema som ofte ble diskutert, var avbrutt søvn og søvnmangel. Egne grunnleggende behov var tilsidesatt.

Mødrene diskuterte steinharde bryst og hvor fælt det var å amme den første tiden. Mor ble rød og sår, og det var smertefullt når barnet tok tak og hugget til. I noen grupper snakket mødrene om tabuer blant barselkvinner. Noen omtalte seg selv som en stabeis, de ville holde ut, og at det derfor kunne bli ekstra ille: «Jeg har aldri hørt om det før, verken at du begynner å blø - eller at du mister litt biter av brystvorten.» Andre mødre kunne ta opp hvor alle tilfredse og hadde god selvfølelse. Opplevelse av å komme til kort hadde sammenheng med et fjerde atferdsmønster, som handlet om anerkjennelse.

\section{Søker anerkjennelse}

Dette mønsteret inkluderte a) søker respekt og forståelse, b) vil bli sett og lyttet til. Mødrene søkte bekreftelse på at de gjorde «rett» og at de var en god mor. Mange hadde følelsen av ikke å bli møtt som en person under sykehusoppholdet. De fikk lite støtte og praktisk hjelp fra personalet og lite ro og hvile på flersengsstuer. Mødrene var forvirret og usikre over motstridende informasjon og ville reise hjem. De opplevde at integriteten deres var truet: «Hva er det som er morbarn-vennlig? Å slenge oss ut like etter fødselen? Å ikke få ha far med? Å stenge barselhotellet? Å få inn en ny hver gang jeg ber om hjelp ved ammingen?»

Med dette i minnet var de følsomme for hvordan helsetjenesten videre møtte dem. Et gjennomgå- ende samtaleemne var at mødrene ville bli sett og lyttet til og tatt på alvor. De uttrykte svært tydelig at de ikke ville bli sett på som masete eller «unormale». De som opplevde at helsesøster lyttet og tok deres spørsmål alvorlig var fornøyde med det. For noen hadde barselgruppe på helsestasjonen bidratt til at de følte seg «normale» og bekreftet, at de ikke var alene om sin situasjon.

\section{Konsekvenser}

Prosessen med a) å utvikle kompetanse, b) endre fokus i parforhold, c) tøye tålegrenser og d) søke anerkjennelse var sammenvevd. Noen ganger førte disse prosessene til gjensidig støtte, andre ganger til konflikt. Når konflikter oppsto, motiverte prioritering av nyfødtomsorg barselkvinnene til å finne løsninger. Gapet i barselomsorg ved overgang fra spesialisthelsetjeneste til kommunehelsetjeneste syntes å øke mødres stress og usikkerhet den første tiden hjemme, og influerte på deres sårbarhet og mestring av amming. Tidlig hjemmebesøk synes å minske gapet og økte mødrenes trygghet og kompetanse. Ved kompetanseutvikling eller ved tøyning av tålegrenser eller endring i parforholdet behøvde mødrene bekreftelse på morsrollen, så manglende informasjon og mangel på positiv anerkjennelse stresset dem. Anerkjennelse og støtte påvirket hvor mye de tøyde grensene for hva de tålte.

\section{DISKUSJON}

Våre funn skildrer mødres første tid hjemme med en nyfødt og viser at for å få kontroll over sin situasjon og bevare integritet, setter de egne grunnleggende behov og eget velbefinnende til side og prioriterer omsorg til den nyfødte. Studien beskriver barselomsorg i overgangen fra spesialist- til kommunehelsetjeneste, og selv om noen detaljer 
kan være kjent, er norske forhold ennå lite dokumentert.

Å kvalitetsvurdere en grounded theory krever analyse av kriteriene for om teorien passer, fungerer, er relevant og modifiserbar (27). Mødres handlinger er tolket gjennom å identifisere deres hovedproblemer og strategier. Data er samlet inn i en norsk by med tidlig hjemreise som relativt ny praksis, men uten offentlige retningslinjer for helhetlig barselomsorg for familier med nyfødte. Studier av alenemødre og innvandrermødre kunne gitt ytterligere detaljer. Styrken i studien er imidlertid variasjonen med førstegangs- og flergangsmødre i ulike situasjoner og med ulik demografi. Vi tror derfor at denne grounded theory om "prioritering av nyfødtomsorg» passer bra til mødres erfaringer, men kan modifiseres når nye data utvikles. Tilbakemeldinger fra presentasjoner på konferanser $\mathrm{i}$ inn- og utland tyder på at studien er relevant. Vi tror videre at studien fungerer godt som en metode for å forklare barselkvinnenes erfaringer.

Utvikling av kompetanse i morsrollen var viktig, men mange erfarte at de var lite forberedt på den første tiden hjemme. De manglet informasjon om barseltiden og om hva som var normalt angående seg selv og barnet. Praktisk øvelse, informasjon og støtte like etter fødselen syntes å være minimal og tilfeldig. Dette er også dokumentert av andre $(8,13,31-32)$. I sin streben etter å øke egen kompetanse på «det normale» bør mødre og fedre derfor kunne øve seg og få veiledning fra helsepersonell som har tid, kompetanse og som kommuniserer godt i møte med familien. Vår studie viser i tillegg en usynliggjøring av overgangsfasen mellom spesialist- og kom- munehelsetjenesten, der behov for helsepersonells innsats kan synes undervurdert og barselkvinnen overlatt til seg selv.

Funnene viste at under kategorien kompetanseutvikling pekte amming seg særlig ut, og tyder dermed på å være sentralt for mødrene. Det var knyttet mye sårbarhet og morsfølelse til ammingen, på godt og ondt, der vellykket amming syntes å være et triumfkort for kvinnen. Ved tidlig hjemreise er ammingen ennå ikke etablert, og det var tilfeldig hvor raskt og hvilken oppfølging de fikk hjemme. Annen forskning viser at de første dagene kan være avgjørende for mor (34-37), det er derfor viktig med rask støtte og individuelt tilpasset oppfølging den første tiden (38-41). En effektiv overføring av tilstrekkelig informasjon fra sykehus til helsestasjoner bør være uproblematisk $i$ en elektronisk verden, noe som gir helsesøster og eventuelt jordmor mulighet til tidlig kontakt.

Kvinnenes endring i parforholdet viste at mor opplevde et sterkt ansvar for den nyfødte, men fars engasjement var viktig for mors velvære og mestring, noe som samstemmer med forskning fra barselavdelinger $(8,9)$, og forskning på fars tilstedeværelse i barnets første år (43). Når mor tøyde sine tålegrenser, var fars forståelse og anerkjennelse sentral. Mødrene ønsket å framstå som at de ikke hadde noen særlige problemer og være flinke, men diskuterte likevel følsomme emner og sårbarhet. Andre studier rapporterer at 60 prosent av mødre med to måneders gamle barn hadde alvorlig søvnmangel, og søvnmangel er et risikomoment for barseldepresjon (4445). Også ammeproblemer kan bidra til barseldepresjon $(44,46)$ og bekrefter således kvinners sårbarhet i barseltiden.
Våre funn tyder på at omorganisering av barselomsorgen i spesialisthelsetjenesten har slått uheldig ut for noen kvinner. Fleksibilitet og forutsigbarhet bør derfor diskuteres innen fødsel- og barselomsorgen for å lette situasjonen for foreldre. Selv om det er normalt å føde barn, er det også normalt å være sårbar og sliten etter en fødsel (7, 16, 30-31). Denne studien viser at mange av mødrene havnet i et «tomrom» i overgangen mellom spesialisthelsetjeneste og kommunehelsetjeneste, noe som kan tyde på en usynliggjøring av barselkvinnens behov og at man undervurderer sårbarheten i denne fasen.

\section{KONKLUSJON}

«Prioritering av nyfødtomsorg» står for hvordan mødre håndterer sitt problem med å bevare kontroll og integritet gjennom å utvikle kompetanse, endre fokus i parforholdet, tøye sine tålegrenser og søke anerkjennelse. Det å lykkes med amming synes å være en særlig følsom og viktig del av morsrollen, og for å lykkes med amming og gi omsorg til barnet, kan mødre ignorere grunnleggende behov hos seg selv som å spise og sove og utholde smerter. Forestillingen om at det er normalt å føde barn kan ha ført til undervurdering av foreldres behov den første sårbare tiden og forhindret et helhetlig tilbud for profesjonell omsorg og informasjon. Et velfungerende samarbeid mellom spesialisthelsetjeneste og kommunehelsetjeneste vil kunne lette situasjonen, slik at mødre ikke er alene i prioritering av nyfødtomsorg og slipper å tøye strikken for langt.

Deler av datamaterialet i artikkelen er publisert tidligere. Se: http://onlinelibrary.wiley.com/doi/10.1111/ j.1471-6712.2012.00974.x/abstract 


\section{REFERANSER}

1. Helsetilsynet. Korleis tek fødeinstitusjonen og kommunen vare på behova til barselkvinna og det nyfødde barnet $\mathrm{i}$ barseltida? Oslo. 2011.

2. Eberhard-Gran M, Slinning K. Nedstemthet og depresjon i forbindelse med fødsel. Oslo: Folkehelseinstituttet. 2007. 3. Harwood K. McLean N, Durkin K. Firsttime mothers' expectations of parenthood: what happens when optimistic expectations are not matched by later experiences? Developmental Psychology. 2007; 431-12.

4. Leahy-Warren P. First-time mothers: social support and confidence in infant care. J Adv Nurs. 2005; 50: 479-488.

5. Leahy-Warren P, McCarty G, Corcoran P. First-time mothers: social support maternal parental self-efficacy and postnatal depression. J Clin Nurs. 2011; 21 : 388-97.

6. Glavin K, Smith L, Sørum R Ellefsen B. Supportive counseling by public health nurses for women with postpartum depression. J Adv Nurs 2010, 66: 1317-27. 7. Sørensen L, Hall E. Resources among new mothers - early discharged multiparous women. Vård i Norden. 2004; 24 : $20-4$.

8. Rudman A, Waldenström U. Critical views on postpartum care expressed by new mothers. BMC Health Services Research 2007, 5: 178

9. Persson E, Fridlund B, Kvist L, Dykes AK. Mothers' sense of security in the first postnatal week: interview study. J Adv Nurs 2011; 67: 105-16.

10. Fredriksson G, Högberg U, Lundman B. Postpartum care should provide alternatives to meet parents' need for safety. active participation and «bonding». Midwifery. 2003; 19: 267-76.

11. Thompson JF, Robert CL, Curri M, Elwood DA. Prevalence and persistence of health problems after childbirth: association with parity and method of birth. Birth. 2002; 29:83-94

12. Nystrøm K, Ohrling K. Parenthood experiences during the child's first year: literature review. J Adv Nurs. 2004:46 (3): 319-30.

13. Fishbein EG, Burggraf E. Early postpartum discharge: How are mothers managing? J Obstet Gynecol Neonatal Nurs1998; 27: 142-8

14. Häggman- Laitila A. Early support needs of Finish families with small children. J Adv Nurs. 2003; 41:494-606.

15. deMontigny F, Lacharité C. Perceived parental efficacy: concept analysis. J Adv Nurs. 2005; 49:387-96.

16. Forster DA, McLachlan HL, Ryan J, Yelland J, Gold L, Rayner S. The early postnatal period: exploring women's views, expectations and experiences of care using focus groups in Victoria, Australia. BMC Pregnancy and Childbirth 2008; 8: 27.

17. Waldenstrøm U. Early discharge as voluntary and involuntary alternatives to a longer postpartum stay in hospital - effects on mothers' experiences and breast feeding. Midwifery. 1989; 5 : 189-96.

18. Persson E, Dyke AK. Parents' experience of early discharge from hospital after birth in Sweden. Midwifery 2002; 18: 53-60.

19. Shaw E, Levitt C, Wong S, Kaczorowski J. Systematic of the literature on postpartum care: effectiveness of postpartum support to improve maternal parenting, mental health, quality of life and physical health. Birth; 2006; 33: 210-20.

20. Brown S, Small R, Faber B, Krastev A, Davis P. Early postnatal discharge from hospital from healthy mothers and terms infant. Cochrane Syst Rev 2002;(3):CD002958.

21. Braveman P, Egerter S, Pearl M, Marchi K, Miller C. Problems associated with early discharge of newborn infants. Early discharge of newborns and mothers. A critical review of the literature. Pediatrics. 1995: 96: 716-26.

22. Cheng CY, Fowles ER, Walker LO. Postpartum maternal health care in the United States: A critical review. The Journal of Perinatal Company. 2006; 3: 34-42. 23. Tjora E, Reigstad H. En seks dager gammel pike med vektnedgang. Tidsskr Nor Legeforen 2009; 129: 868-9.

24. Helsedepartementet. Kommunenes helsefremmende og forebyggende arbeid $i$ helsestasjons- og skolehelsetjenesten Oslo: 2004, Veileder til forskrift av 3. april 2003. nr. 450.

25. KOSTRA 2009. Kommune Stat Rapportering, Statistisk sentralbyrå. Oslo.

26. Hjälmhult E, Lomborg K. Managing the first period at home with a newborn: a grounded theory study of mothers' experiences. Scand J Caring Sci. doi: 10.1111/j.1471-6712.2012.00974.x.

27. Glaser BG. Theoretical sensitivity: advances in the methodology of grounded theory. Mill Valley, CA: Sociology Press, 1978

28. Glaser BG. The grounded theory perspective III: theoretical coding. Mill Valley, CA: Sociology Press, 2005.

29. Morgan DL. Focus groups. Annual Review of Sociology 1996; 2: 129-52.

30. Kvale S, Brinkman S. Learning the craft of qualitative research interviewing. London: Sage Publications, 2009.

31. Nysæther H, Bærug A, Nylander G, Klepp KI. Barna inne natt og dag - er barselkvinnene fornøyde? Tidsskr Nor Legeforen2002; 122: 1206-9.

32. Mac Arthur C. What does postnatal care do for women's health? Lancet 1999; 353: 343-4.

33. Kronborg $H$, Væth $M$. The influence of psychosocial factors on the duration of breastfeeding. Scand J Caring Sci 2004; 32: 201-16.

34. Larsen JS, Hall EOC, Aagaard H.
Shattering expectations: when mothers confidence in breastfeeding is undermined - a metasynthesis. Scand J Caring Sci 2008; 22: 653-61

35. Grassley J, Nelms T. Understanding maternal breastfeeding confidence: a Gadamerian hermeneutic analysis of women's stories. Health Care Women Int 2008; 23: 841-62

36. O'Brien M, Buickstra E, Hegney E. The influence of psychological factors on breastfeeding duration. J Adv Nurs 2008; 6: 397-408.

37. Häggkvist AP, Brantsæter AL, Grjiboviski AM, Helsing E, Meltzer HM, Haugen M. Prevalence of breastfeeding in the Norwegian Mother and Child Cohort Study and health service-related correlates of cessation of full breast-feeding. Publ Health Nutr 2010; 13: 2076-86.

38. Goulet L, D'Amour D, Pineault R. Type and timing of services following postnatal discharge: do they make a difference? Women Health 2007; 45:19-39.

39. Tufte E. Norske kvinners ammeproblem. Masteroppgave. Nordiska högskolan för folkhälsovetenskap. Göteborg. 2005.

40. Jansson AK, Pettersson K, Udèn G. Nurses' first encounters with parents of new-born children - public health nurses views of a good meeting. J Clin Nurs 2001; 10: $140-51$

41. Jansson AK, Sivberg B, Wilde Larsson $B$, Udèn G. First-time mothers' satisfaction with early encounters with the nurse in child health care: home visit or visit to the clinic? Acta Pædiatr 2002; 91: 571-7.

42. Hjälmhult E. Skal helsesøster tilby hjemmebesøk til alle foreldre med nyfødt barn? Sykepleien Forskning. 2009; 1:18-26 43. Fägerskiöld A. A change in life as experienced by first-fathers. Scand $J$ Caring Sci; 2008; 22: 64-71.

44. Dørheim S, Bondevik GT, EberhardGran M, Bjorvatn B. Sleep and depression in postpartum women: a populationbased study. Sleep 2009;32: 847-55.

45. Ross LE, Murray BJ, Steiner MJ. Sleep and perinatal mood disorders: a critical review. Psychiatry Neurosci2005; 30: 247-56.

46. Eberhard-Gran M, Eskild A, Tams K, Samuelsen S0, Opjordsmoen S. Depression in postpartum and non-postpartum women: prevalence and risk factors. Acta Psychiatr Scand 2002; 106: 426-33.

47. Edhborg M, Friedberg M, Lund W, Widstöm AM. Struggling with life: Narratives from women with signs of postpartum depression. Scand J Publ Health 2005; 33: 261-7.

Les kommentaren på side $231 \quad \gg$ 